\title{
Study of Sensor Deflection in Hip Simulator : Numerical and Experimental Method
}

\author{
Fabian Singgih Wicaksono ${ }^{1, *}$, T Towijaya ${ }^{1}$, Eko Saputra $^{3}$, Rifky Ismail ${ }^{3}$, Mohammad Tauviqirrahman ${ }^{3}$, J \\ Jamari $^{2}$, and Athanasius P. Bayuseno ${ }^{2}$ \\ ${ }^{1}$ Magister Program of Mechanical Engineering, Diponegoro University, Semarang - Indonesia \\ ${ }^{2}$ Department of Mechanical Engineering, Faculty of Engineering, Diponegoro University, Semarang - Indonesia \\ ${ }^{3}$ Laboratory for Engineering Design and Tribology, Department of Mechanical Engineering, Faculty of Engineering, \\ Diponegoro University, Semarang - Indonesia
}

\begin{abstract}
A lot of Hip Joint Simulator have been made nowadays, most of them use different structure and method. This research reports a pin-on-ring tribometer design that is used to became hip joint simulator based on the movement of the salat (salat gait). Modified femoral head and acetabular cup holder are performed, to design a reciprocating motion for simulation of artificial hip movement. An interesting finding from this study is a new linked-bar mechanism that leads to the ability to move femoral head against the acetabular cup and measure wear volume of an THR patients during normal salat gait. The designed motion angle is $121.5^{\circ}$ in the flexion direction and $15.5^{\circ}$ in the direction of abduction. Linked bar for sensor dial indicator have enough adjustment, but there is still a movement that is not rigid upon running hip joint process simulator. This research concentrates on the bar is already linked in accordance or not when compared with the data in the simulate on a computer. Estimation error and deviations that occur between numerical and experimental is going forward to improve hip joint simulator Undip to be more precise and relevant research to use THR Undip.
\end{abstract}

Keywords: hip joint simulator; deflection; linked bar; cantilever; dial indicator

\section{Introduction}

Total hip replacement (THR) is the most successful orthopaedic surgical procedure to replace hip joint in people who experience such as wounded or osteoashtritis in that femoral head/femoral ball and the socket from the hip. Damage to the hip joint can be caused by inflammatory processes, aging or injury. Permanent damage to the hip joint action entails replacement with artificial hip joint. In developed countries, the number of patients using artificial hip bone connection. In Indonesia, the survey data and field observations have been made at RS. dr. Soeharso Orthopaedical hospital place in Solo referent Orthopaedic in Central Java and one of the best hospitals in the national level orthopaedic. The results of the survey showed the number of artificial hip joint replacement in the hospital reaches 400 people per year. When combined nationally, the amount of reimbursement is still relatively small compared to the number of substitutions in the developed countries.

Biomaterial that made artificial hip joint generally of metal/ceramic for femoral head and metal/ceramics/uhmwpe for acetabular cup/cell. Material selection and design of components/materials is an important factor for reliability, performance and long- term durability of total hip replacement. Wear of the acetabular cup is a very important issue, especially at a time when the conditions of loosening of the fixation. A lot of research and experiments have been done about the measurement of wear of the acetabular cup using a simulator that is common to get the value of wear based on the movement of people walk (walking gait). Therefore special research need to compute or test the wear to get the value of wear based on the movement of people praying (salat gait). To do this, it requires a special simulator to create a movement that resembles the movement of prayer (salat gait).

The previous researches have been researching about the hip joint in numerical analysis and finite element method [1-4]. This research starts from a survey of literature from various writings/paper by many previous researchers. Next, take a particular case that has been done before as an adjacent literature data theme with the design that will be done. Then, determine the modification of pin-on-ring tribometer to achieve the desired purpose, namely artificial hip test tool with the ability to mimic the movement of walking gait and gait salat. The ability to imitate a walking gait is aiming to get the validation value with the previous test. After it determines the design plan in any modifications, design plans were chosen through the method of morphology to

* Corresponding author: fabiansinggih@gmail.com 
generate an optimal design. After the hip joint simulator already so attached and then researched back special parts and crucial that support validation of each measurement to perform hip joint simulator.

The next step is concentrated on the linked bar on that the hip joint simulator made, affected by the force directly from the cantilever pneumatic and touching the dial indicator to the reading of the gait cycle one prayer. So the researcher needs to be done in particular to know the deflection that occurs in the bar and linked the estimation error of the sensor readout as well as the deviation of measurement occur. When measuring deviations happened still within limits, improvised tools in hip joint simulator does not need to be done on a massive.

\section{Introduction}

\subsection{Experimental Method}

Starting with the values obtained with the least squares technique, Murthy and Abdin (1980) carried out a search for the minimum using the Monte Carlo technique or simplex method. This method always requires a longer computational time than the least squares technique. Fukuda and Shimakahbe (1984) also made an exhaustive search for the minimum value using minimax approximation. The minimax approximation technique is reported to take longer than the least squares method for straightness and flatness, but less time for roundness and cylindricity, that is, the time required for a large amount of data is shorter thanwith the least squares technique.

In some attempts normal deviations are considered to obtain the ideal geometrical feature and the form errors are computed on this basis. To demonstrate the effectiveness of the method, these values are compared with the errors obtained using the linearized deviations. If the comparison and interpretation are not done properly, however, confusion can arise because of the fundamental difference in the definitions of the deviations. [5]

Stage of this activity starts from preparing specimens of acetabular linear product in the laboratory of mechanical engineering of the University of Diponegoro EDT and hip joint simulator itself. In this study the process of testing conducted in the Laboratory of Tribology Design and Engineering of the University of Diponegoro. Processing, Data analysis and discussion of the data obtained were from processed by using the appropriate statistical methods then poured in tables, charts, and images.

\subsection{Numerical Method}

A numerical method by simulating the cases into modeling in accordance with program used. Then the next results from modelling were analyzed with theories that already exists. This analysis using the method element to (MEH) and use Solidworks software.

\section{The Hip Joints Simulator}

Pin-on-ring Tribometer Undip is designed into a simulator transducer for the movement of people in prayer. The two main movements gait to be made on the design of the research is flexion-extension and abduction-adduction (Two DOF/Degree of Freedom). Some of the designs that should be made, namely: holder and swing Femoral Head in the direction of F-E. Holder and swing Femoral Head in the direction of A-A, the drive shaft in the direction of F-E, and the drive shaft in the direction of A-A. Fig 3.1 Shows of transducer F-EA-A 2-DOF tangent. The angle is the angle $\phi$ flexion/extension, the angle $\beta$ is the angle of the abduction/adduction. Following the results of a final design that was made and used in the laboratory of EDT University of Diponegoro shows in Fig. 3.2.

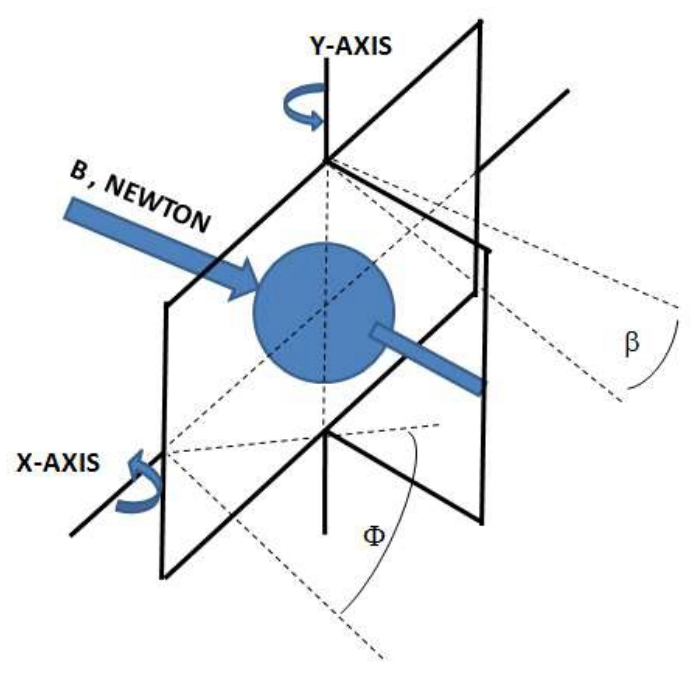

Fig. 3.1 Bar diagram mechanism

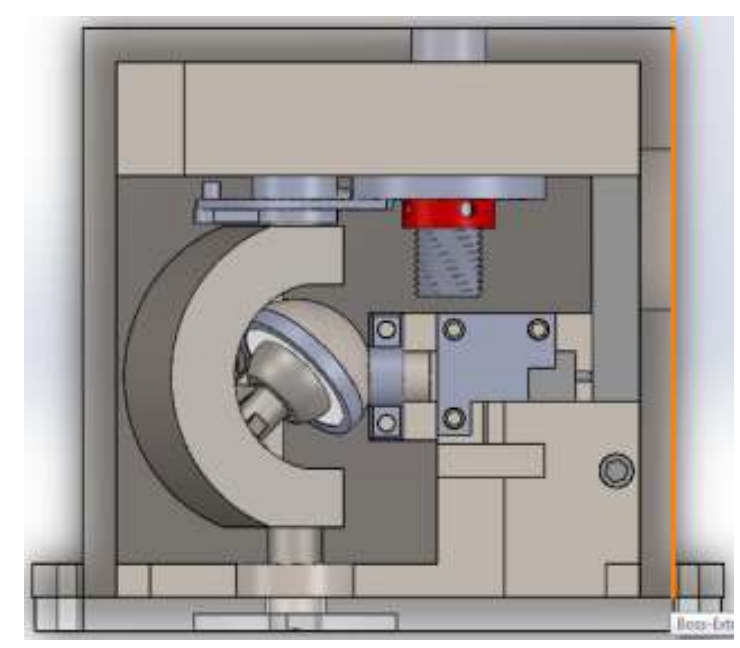

Fig 3.2 Final design Hip Joints Simulator Undip.

Linked a cantilevered bar has been tangent experienced the lack of relevance data are read on the censorship dial indicator affected by deflection. The length of the bar is linked also greatly affect the reading of data from the workpiece measured heading into dial indicator data read. With that mechanism, hip joint simulator have some more reliable measurements to be 
more comperhensive data that will be obtained from after running simulator for salat gait cycle.

\section{Results}

We obtained that the affect of deflection of cantilever beam affect the wear depth of acetabular liner. We use 30.000 cycle with variant force $400 \mathrm{~N}$ and $800 \mathrm{~N}$. In the Fig 4.1 shows the part Cup Holder assembly in the Hip Joint Simulator and so Fig 4.2 shows the deflection that affect the cup holder during process salat or movement gait cycles use numerical method simulation.

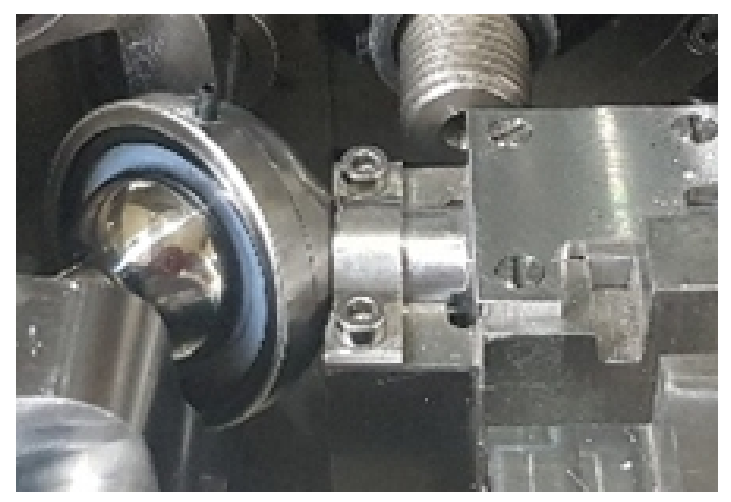

Fig 4.1 Cup holder in Hip Joint Simulator

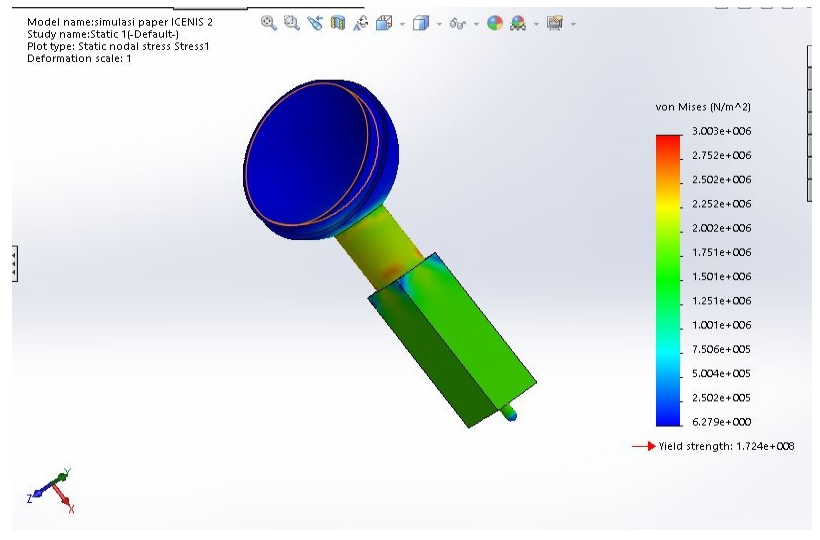

Fig 4.2 Cup holder part affect by deflection.

The data obtained can be concluded that two parameters of force applied showed different results. On the imposition of $400 \mathrm{~N}$ and $\mathrm{N} 800$, both of whom scored consecutive depth $0,652 \mathrm{~mm}$ and $0,673 \mathrm{~mm}$ and on 30,000 cycles, but for the imposition of $800 \mathrm{~N}$ gets higher grades. From the beginning of the test until the end, the resulting data also shows that the imposition of $400 \mathrm{~N}$ wear depth value smaller than $800 \mathrm{~N}$.

At 5,000 cycles, the wear on the imposition of $400 \mathrm{~N}$ about $0,15 \mathrm{~mm}$, while the imposition of $800 \mathrm{~N}$ a little bit higher than $0.2 \mathrm{~mm}$. significant differences Occur in cycles between 5,000 and 15,000 cycles. Can be seen at 10,000 cycles the value of wear depth at $0.35 \mathrm{~mm}$ when loading $400 \mathrm{~N}$. but on the imposition of $800 \mathrm{~N}$ found very large depth wear slightly below $0.5 \mathrm{~mm}$.

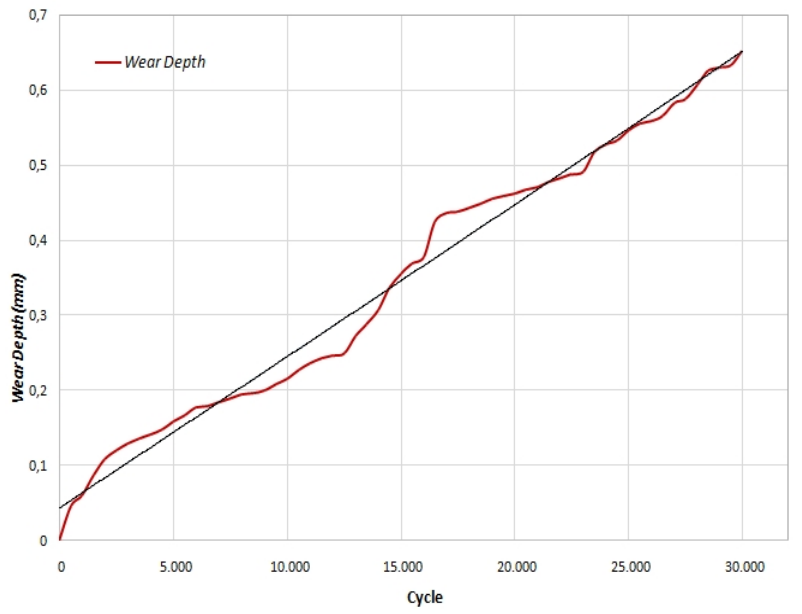

Fig 4.3 Result of wear depth with force 400N.

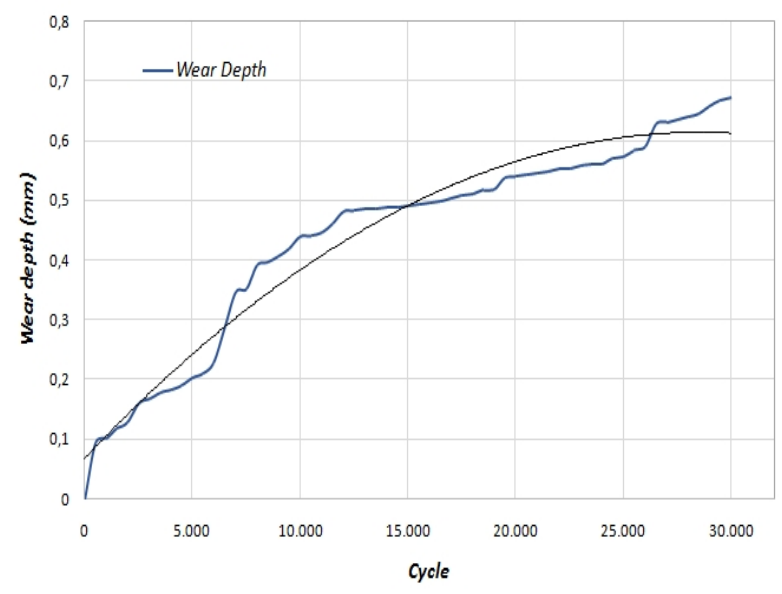

Fig 4.4 Result of wear depth with force 800 N.

\section{Discussion}

A good testing data should show the same trend on these two parameters. But in this test, there are some problems so that the graph of the test results did not indicate a trend. The first cause, is a tool that made still less precision and less center at the center of the femoral head with the acetabular cup. The value of not centered is $0,035 \mathrm{~mm}$. This led to the sensors on the machinestyle testing was moving back and forth a little while given style. The second is due to the onset of plastic deformation on acetabular cup results, so that the reading of the dial indicator to be slightly biased. But things are not too influential because the data retrieval wear depth is at the normal position reading sensor/early movement.

From this results it can be concluded that the research deviation which occurs at the hip joint simulator which is caused by the influence of deflection not very significantly affect results of testing the wear depth. So, data that has been produced from the hip joint simulator software is arguably still good and comprehensive. And also manifest the development of life low carbon society to better future country's development. 


\section{References}

1. E. Saputra, I. Budiwan Anwar, R. Ismail, J. Jamari and E. van der Heide, Jurnal Teknologi (Sciences and Engineering) 66(3), pp 53-58 (2014)

2. I. B. Anwar, A. Santoso, E. Saputra, R. Ismail, J. Jamari and E. van der Heide, Advanced pharmaceutical bulletin 7(2), p 335 (2017)

3. R. Ismail, E. Saputra, M. Tauviqirrahman, A. B. Legowo, I. B. Anwar and J. Jamari, Applied Mechanics and Materials 493, pp 426-431 (2014)
4. I. B. Anwar, E. Saputra, R. Ismail, J. Jamari, E. Van der Heide ,M. J. B. Ghazali and M. F. B. Abdollah, Proceedings of Malaysian International Tribology Conference, pp 56-57 (2015)

5. N. Venkaiah, M.S. Shunmugam, International Journal of Machine Tools and Manufacture, 47(78), pp 1229-1236 (2007)

6. J.J. Kauzlarich, J.A. William, Proceedings of the Institution of Mechanical Engineers, Part J: Journal of Engineering Tribology, 215: 387 (2001)

7. Van Beek, A. 2012. Advanced Engineering Design, Lifetime Performance and Reliability. Delft, Netherland: TU Delft. 